\title{
A new perspective to model subsurface stratigraphy in alluvial hydrogeological basins, introducing geological hierarchy and relative chronology
}

\author{
Chiara Zuffetti $^{* 1}$, Alessandro Comunian ${ }^{2}$, Riccardo Bersezio ${ }^{1}$, Philippe Renard ${ }^{3}$ \\ 1 Dipartimento di Scienze della Terra, Università degli Studi di Milano, via L. Mangiagalli 34, 20133 I-Milano, Italy \\ 2 Dipartimento di Scienze della Terra, Università degli Studi di Milano, via Cicognara 7, 20129, I-Milano, Italy \\ 3 Centre for Hydrogeology and Geothermics, University of Neuch^atel, 11 Rue Emile Argand, CH-2000, Neuchatel, Switzerland
}

Keywords: Alluvial stratigraphy, Hierarchy, Modelling rules, Po basin, Python, Relative chronology

\section{Highlights}

- Geological knowledge converted into modelling rules within an automatic routine.

- HIEGEO implements hierarchic stratigraphic approach to model nested alluvial units.

- Strong and traceable linkage between modelled geometries and their geological origin.

- Representation of geological architecture at different degrees of detail.

- Free and open source, applicable to different contexts, extensible to 3-D modelling.

\begin{abstract}
This paper presents a novel perspective for modelling alluvial stratigraphy. It integrates the spatial geological information, geological maps and welllog descriptions, with the rules describing the hierarchy and relative chronology of the geological entities. As geological modelling tools are moving fast forward, the urgent need for expert geological input, codified as modelling rules, persists. Concerning subsurface alluvial architectures, the concepts of "stratigraphic hierarchy" and "relative chronology" provide the most relevant rules which permit to link the modelling procedure to the geo-history of a region.

The paper shows how to formalize this knowledge into modelling rules. This is illustrated and implemented in a Python ${ }^{\mathrm{TM}}$ module named HIEGEO which is applied on a 2-D cross-section from the Po Basin (N-Italy). The stratigraphic correlation yields 2-D pictures of the hierarchic stratigraphy and relative chronology of the units. The input are: an attribute table of stratigraphic boundaries expressing their hierarchy and chronology; contact points where these boundaries cross the control logs. Since the aim of HIEGEO is to illustrate the principle of the method but not to replace existing 3-D geological modelling tools, it implements a linear interpolation algorithm which creates joins between contact points. It plots linear joins framing polygons based on their hierarchy, at any user's desired detail. HIEGEO highlights potential inconsistencies of the input dataset, helping to re-evaluate the geological interpretation.

The proposed workflow allows to: i) translate geological knowledge into modelling rules; ii) compute stratigraphic models constrained by the hierarchy of stratigraphic entities and the relative chronology of geological events; iii) represent internal geometries of the stratigraphic units, accounting for their composite nature; iv) reduce uncertainty in modelling alluvial architectures. It represents a starting point for multi-scale applications and could be easily integrated into 3-D modelling packages, to couple the hierarchical concept proposed here with existing advanced interpolation methods.
\end{abstract}

\section{Rationale and aims of the work}

Modelling the alluvial stratigraphy of sedimentary basins is important for many applications, like management of groundwater and shallow geothermal resources, or geohazard evaluation. The stratigraphic architecture of alluvial basins derives from multiple geological processes, acting at different spatial and temporal scales. The result is a nested, hierarchical arrangement of the sedimentary bodies and their internal heterogeneities: highest-hierarchy and large stratigraphic units are built-up by several component units of progressively lower size and hierarchy (Blum and T€ornqvist, 2000; Bridge, 2003; Miall, 1996, 1985). The current geo-modelling approaches aim to preserve this geological complexity. Most of literature acknowledges that multi-scale modelling of the geological architectures is made possible by the thorough use of the geological knowledge (Bond, 2015; Calcagno et al., 2018; Caumon, 2010; Dalman and Weltje, 2008; Gallerini and De Donatis, 2009; Mackey and Bridge, 1992; Macrae et al., 2016; Perrin and Rainaud, 2013; Turner, 2006; Wellmann et al., 2014; Wijns et al., 2003).

The need for expert geological input to the modelling stages is a persistent argument made by many modelling approaches (Randle et al., 2018; Russell et al., 2019 and references within). However, it is very difficult at present to formalize and express the geological constraints in a quantitative and objective way (Brodaric and Gahegan, 2001; Wellmann and Caumon, 2018 and references within). On the one hand, explicit modelling approaches widely rely on expert-driven interaction and manual implementation, thus 
being time-intensive and often addressing relatively simple geological configurations (deKemp et al., 2007; Lemon and Jones, 2003; Schetselaar et al., 2016). On the other hand, implicit modelling software rely on coded rules driving interpolation functions (superposition/erosion between vertically-ordered geological entities; examples in Calcagno et al., 2008; Chiles et al., 2004; de la Varga et al., 2018). Yet, they do not permit either to model multiple levels of hierarchy, and/or to visualize contemporaneously all the ranks after a single interpolation (e.g. Zuffetti, 2019). Also, many different geostatistical simulation methods were developed to implement hierarchical approaches in modelling alluvial settings (Comunian et al., 2011, 2016; Dell'Arciprete et al., 2012, 2010; Jussel and Stauffer, 1994; Zappa et al., 2006). But even in these cases, mostly the geometrical component of the site-specific geological information is introduced, while the relevant knowledge about the hierarchical arrangement and geo-history of the stratigraphy, are hardly considered in a straightforward manner. Hence, recognizing the modellers' desire for maximum geological plausibility, a novel approach to analyse, describe, and code geological knowledge of alluvial stratigraphy in model-building process is needed. Here, we propose to adopt two key-concepts to interpret the geology of a basin: hierarchy of stratigraphic entities and relative chronology of the geological evolution. The "hierarchy" (or rank) of the stratigraphic entities (Aigner et al., 1999; Gardner, 1995; Heinz et al., 2003; Huggenberger and Aigner, 1999; Miall, 1985; Weber, 1986), depends on the duration and rate of deposition vs. erosion. The sequence of increments through time of the geological evolution represents the "relative chronology" of the geological processes. In a basin fill, it is expressed by the three basic relationships among the stratigraphic boundaries and bodies with different hierarchy, i.e. intersection, superposition and juxtaposition.

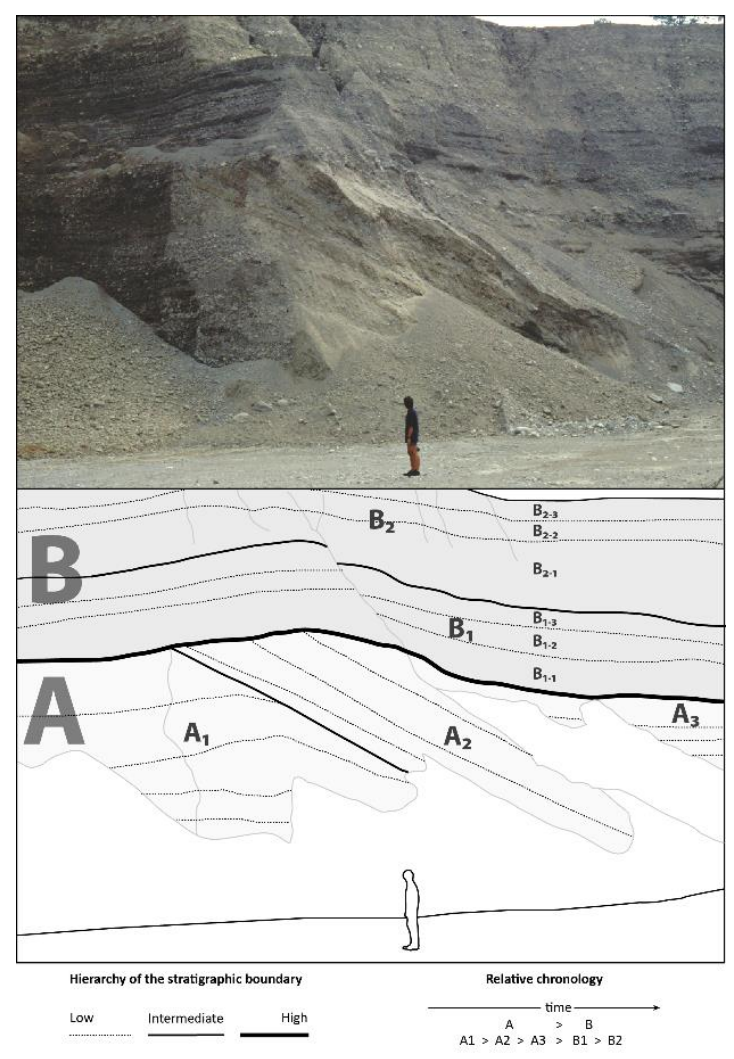

Fig. 1. Exposed analogue of Pleistocene glacio-fluvial stratigraphy (quarry exposure in the Ticino river valley, Northern Italy; after Bersezio et al., 1999). In the lower frame, line-drawing shows the hierarchic assemblage of the stratigraphic units. A and B: stratigraphic units. Subscripts identify the decreasing stratigraphic hierarchy. Note the hierarchy of the cross-cut relationships between the stratigraphic boundaries.

The hierarchy of the stratigraphic units links the sedimentary architecture and processes to the chronology of increments of the geological evolution of any studied setting. These two variables represent the outstanding geological rules for reconstructing and modelling sedimentary basins, specifically in the alluvial sequences, which are characterized by systematic cross-cut and juxtaposition relations among the depositional bodies. Substantial help in modelling subsurface stratigraphy comes from the study of exposed analogues of subsurface sediments (Fig. 1), which provide clues to define stratigraphic hierarchy and relative chronology of the geo-history (examples in Bayer et al., 2011; Bersezio et al., 1999, 2007 among many others).

The example given in Fig. 1 illustrates these two concepts in the case of an exposed gravel-sand, glacio-fluvial assemblage of sedimentary bodies. It is a typical outcrop analogue of many peculiar features of the buried stratigraphy of many Quaternary hydrogeological basins worldwide. In this example, the three-fold hierarchy is visualized by the sub-planar erosional boundary between the two high-hierarchy stratigraphic units (A and $\mathrm{B}$ ), which cross-cuts the intermediate-hierarchy stratigraphic units nested within A (A1, A2, A3) and the differently-dipping intermediate-hierarchy boundaries between them. The contacts between coarse-over fine-grained sedimentary bed-sets permit to recognize the low-hierarchy sediment packages nested within the intermediatehierarchy units A1, A2, A3, and B1, B2 (e.g. B2-1, B2-2, B2-3 within B2; Fig. 1). The line-drawing at the outcrop, and interpretation of the observed stratigraphic geometries and mutual relationships, permits to set-up the hierarchy and the relative chronology of erosional/depositional events, and hence to describe the geological evolution. The geological knowledge, which includes the geo-history of the specific settings under investigation, is contained into the hierarchy and relative chronology concepts.

Here we propose to formalize this geological knowledge in computer codes to constrain geo-modelling. The addressed issues are: i) how to formalize hierarchy and relative chronology derived from the geological reconstructions? ii) how can this knowledge be included into an automated modelling workflow? iii) how to easily test alternative hypotheses of geological evolution in automated ways? The specific aim of this paper is to set-up and demonstrate a work-flow to introduce hierarchy and chronology into computation of realistic models of subsurface architectures in alluvial basins, whose geological complexity lies in the nested structure of composite sedimentary bodies. The method is specifically conceived to assist geo-modelling of hydrogeological basins. It is performed starting from geological models that consist of a fence of cross-sections, the latter obtained from highly-uncertain and even low-confidence correlation of 1-D borehole logs. 
This paper introduces a Python ${ }^{\mathrm{TM}}$ module named HIEGEO (hierarchical geo-modelling) that illustrates the proposed approach. It integrates the new rules with hard and soft geological information. HIEGEO produces a hierarchic stratigraphic model constrained by the hierarchy of the stratigraphic entities and the relative chronology of geological events. Its working principles are demonstrated on a simple example, in which a real-world 2-D stratigraphic cross-section is reproduced by applying the new rules and work-flow.

We selected a simple 2-D example, because the focus of this work is to demonstrate a hierarchical approach to constrain the geo-modelling process, rather than an attempt to propose a completely new 3-D geological modelling tool. Instead, we think that the proposed framework could be integrated in such already existing platforms. The case-study is located in the Quaternary Po alluvial Basin (Northern Italy), whose subsurface glacio-fluvial architecture exemplifies the stratigraphy of a wide number of hydrogeological basins around the world. Moreover, the topological relationships and depositional processes interpreted at this site are akin to the outcropping analogue presented in Fig. 1 and can be applied elsewhere, at any scale of investigation.

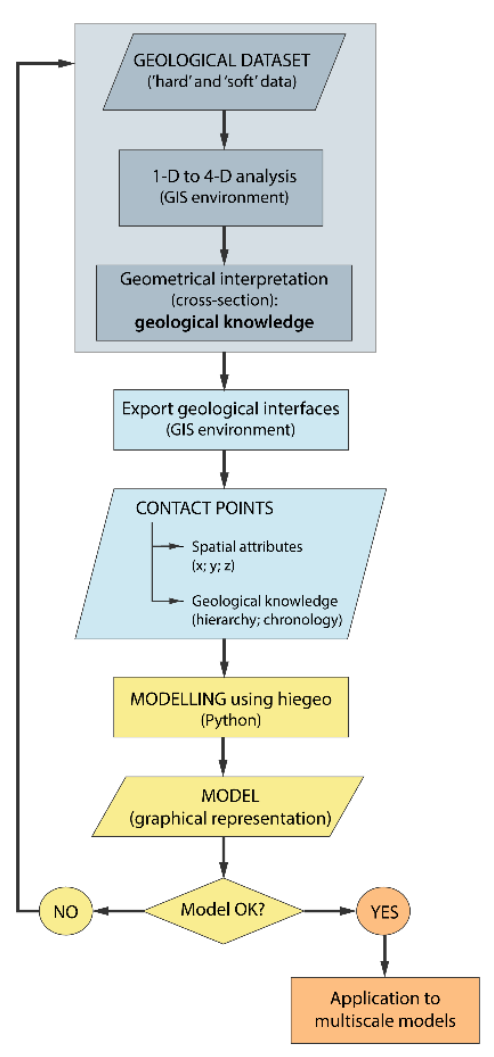

\section{General workflow}

The proposed workflow is illustrated in Fig. 2. It involves three main steps: the geological interpretation of the data-set in terms of hierarchy and relative chronology rules; the coding of these data using a standardized framework; the computation of the set of interfaces honouring the observations and the presented rules. As for most geological modelling studies, field and subsurface data represent the starting point. The dataset is organized using a GIS, which permits to manage scale, dimensionality, relative chronology, and to prepare the data for further processing. The workflow is fully applicable using any of the available open source GIS suites.

The example we present has been managed with ESRI ArcGIS. The cross-sections are obtained by manually correlating the subsurface stratigraphic logs driven by geometrical and genetic rules. The geological knowledge is numerically expressed in terms of hierarchy and relative chronology of the stratigraphic units (Figs. 1 and 3). Finally, all the available information is processed with HIEGEO. It provides a graphical representation of the geological model. If the model is satisfactory, then it will become the input of further modelling steps (i.e. hydrogeological models); alternatively, one should go back to the interpretation, or try to collect additional data to clarify unresolved issues. In the following, the workflow is described step by step by tracking an example in the Po Basin. Therefore, we first introduce this example.

Fig. 2. The workflow proposed in the present work. It combines surface and subsurface geological data analysis and interpretation with mathematical multiscale modelling.

\section{Raw data and introduction of the illustrative example}

The dataset used to illustrate the proposed workflow derives from the stratigraphic study of the Quaternary fill of the Po Foreland Basin (Cavalli, 2012; Bersezio et al., 2016, Fig. 3). The selected area belongs to the glacio-fluvial and alluvial terraced landscape at the northern alpine margin of the Po Basin. Its stratigraphic architecture is the result of the progressive southward entrenchment and filling of alluvial valleys into the Pliocene-Lower Pleistocene marine sediments, followed by Middle-Late Pleistocene progradation and terracing of glacio-fluvial fans (Fig. 2-B). Post-depositional deformation consists of gentle southward tilting owing to Quaternary uplift of the Alpine source area of the sediments (Scardia et al., 2012). Folding and faulting are therefore negligible complexities for modelling at this site. In this area, we selected a cross-section that describes gently S-ward dipping, clastic bodies fed from the MiddleLate Pleistocene Alpine glacial amphitheatres of Como, Brianza and Lecco (Bini et al., 2004; units LCN, BE, PEO, BIN, BOZ in Fig. 2B). These sediments sit above pre-glacial, alluvial conglomerates (Early Pleistocene; C in Fig. 2-B) and littoral to shallow marine finegrained sediments (Early Pleistocene; VIM in Fig. 2-B).

The hard data consist in i) a surface geological map at 1:10 000 scale (polygon GIS shapefile; Fig. 3-A), ii) the locations of 10 boreholes (average depth $150 \mathrm{~m}$; point GIS shapefile; Fig. 3-A), iii) the logs of the 1-D borehole stratigraphy, after normalized digitization based on a specifically-built lithotextural alphabetic Code (GIS table; Table 1). The borehole logs are lined-up along a $1 \mathrm{~km}-$ long, N-S stratigraphic cross-section, which runs almost parallel to the average SSE-ward depositional trend of the stratigraphic bodies, orthogonal to the average axial strike of the Po basin (Fig. 3-A). The cross-section is represented by the Cross-section Tool of ESRI ArcGIS®. Vertical sticklogs (Fig. 4) represent the projection of the borehole stratigraphic datum, contained into GIS descriptive tables. 


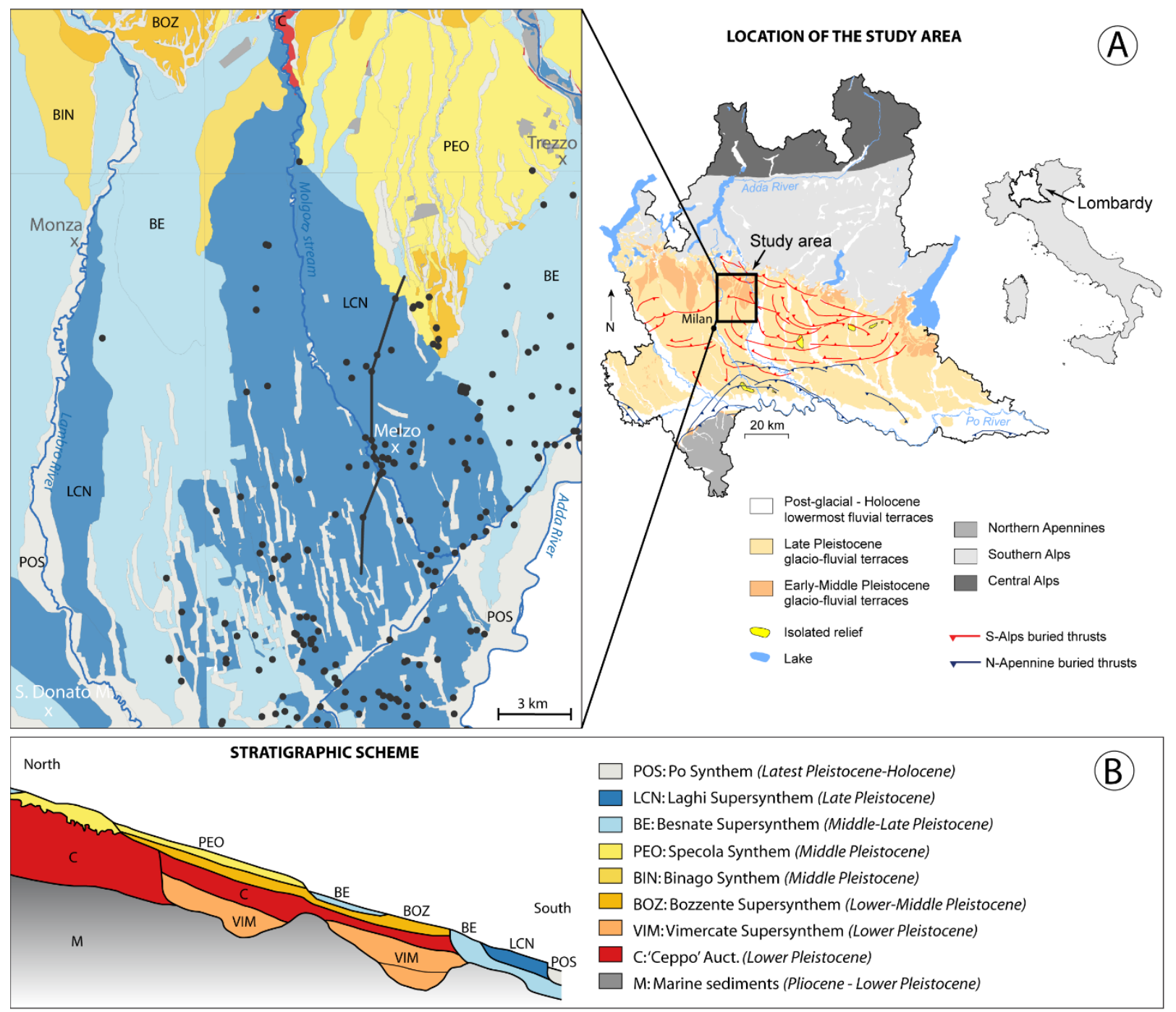

Fig. 3. A) Location and geological setting of the study area in the Po Plain of Lombardy (Northern Italy). The dataset used for the subsurface reconstruction of the study area comprises a surface geological map (redrawn after Bersezio et al., 2014; Bini et al., 2014; Cavalli, 2012; Comizzoli et al., 1969; Francani et al., 2016) and borehole data (black dots). Solid black line: trace of the cross-section shown in Fig. 4. Legend of the geological map as in panel B. B) Stratigraphic scheme of a N-S transect across the Quaternary glacial, glacio-fluvial and alluvial terraces exposed in the northern Po Plain of Lombardy. Modified after Bersezio et al. (2014).

\begin{tabular}{cll}
\hline & Facies code & Example of application \\
\hline $\begin{array}{c}\text { Sedimentary texture } \\
\text { (all observations) }\end{array}$ & $\begin{array}{l}\text { Cong: conglomerate; Ar: } \\
\text { sandstone }\end{array}$ & $\begin{array}{l}\text { SG: sand }>50 \%, \\
\text { gravel }<50 \%\end{array}$ \\
& G: gravel, S: sand, L:silt and & SAL: sand $>$ clay $>$ silt \\
& very fine sand, A: clay & \\
& T: peat, P: pedogenic & \\
concretions (carbonate) & \\
& GS: sandy gravel, SG: gravelly & \\
& sand, SL: silty sand, LS: sandy & \\
& silt & \\
& LAS: clayey-sandy silt & \\
& G/S: interbedding of gravel & \\
and sand & vfSfG: very fine sand \\
Additional textural & vf: very fine & $>50 \%$, fine gravel $<$ \\
codes & f: fine & $50 \%$ \\
& m: medium & mSAL: medium sand \\
& c: coarse & $>$ clay $>$ silt \\
\hline & vc: very coarse & \\
\hline
\end{tabular}

Tab. 1. Lithotextural coding used to normalize the 1-D borehole stratigraphic logs, stored into a GIS Geo-Database.

\section{Formalizing the geological relationships}

\subsection{Interpreting the cross-sections}

The subsurface stratigraphic data are analysed with a rigorous GIS datamanagement method to preserve internal consistency during subsequent elaborations. It involves the following steps:

(1) 1-D analysis (Fig. 4-A). The sharp "coarse-grained above fine-grained" sediment contacts are picked within each borehole, thus subdividing the stratigraphic logs into a sequence of lithotextural intervals, bounded by abrupt textural cont acts (compare to the criteria adopted in Fig. 1). The sediment packages in between two contacts show the basic stacking pattern types (coarseningupwards, fining-upwards, stationary) and represent the 1-D individual genetic units, which formed under different trends and durations of the sedimentary processes. 
(2) 1-D to 2-D propagation: definition and characterization of the 2-D stratigraphic boundaries. Stratigraphic correlation is carried out following the standard criteria of physical stratigraphy (Allen and Allen, 2013; Miall, 1996). After this step, the correlation of the individual 1-D genetic units originates a frame of correlation lines which represent the stratigraphic boundaries of the up-scaled 2D stratigraphic units. At this stage of the work, the stratigraphic units are the 2-D entities framed by stratigraphic boundaries, either erosional or depositional. The lower boundary must be the true stratigraphic base of the unit, the top boundary might correspond to an erosional truncation, omitting the depositional top of the unit itself. This picture honours the hard data and introduces the interpretative 2-D geometry of the stratigraphic units. At this step, it is possible to delineate the hierarchy of the 2-D stratigraphic boundaries and stratigraphic units, by analysing their relationships of superposition, juxtaposition without intersection, and cross-cutting. Relying on this simple scheme, the highest-hierarchy boundaries are those cross-cutting the others. They can merge together or mutually intersect, but cannot be cross-cut by lower-hierarchy boundaries.
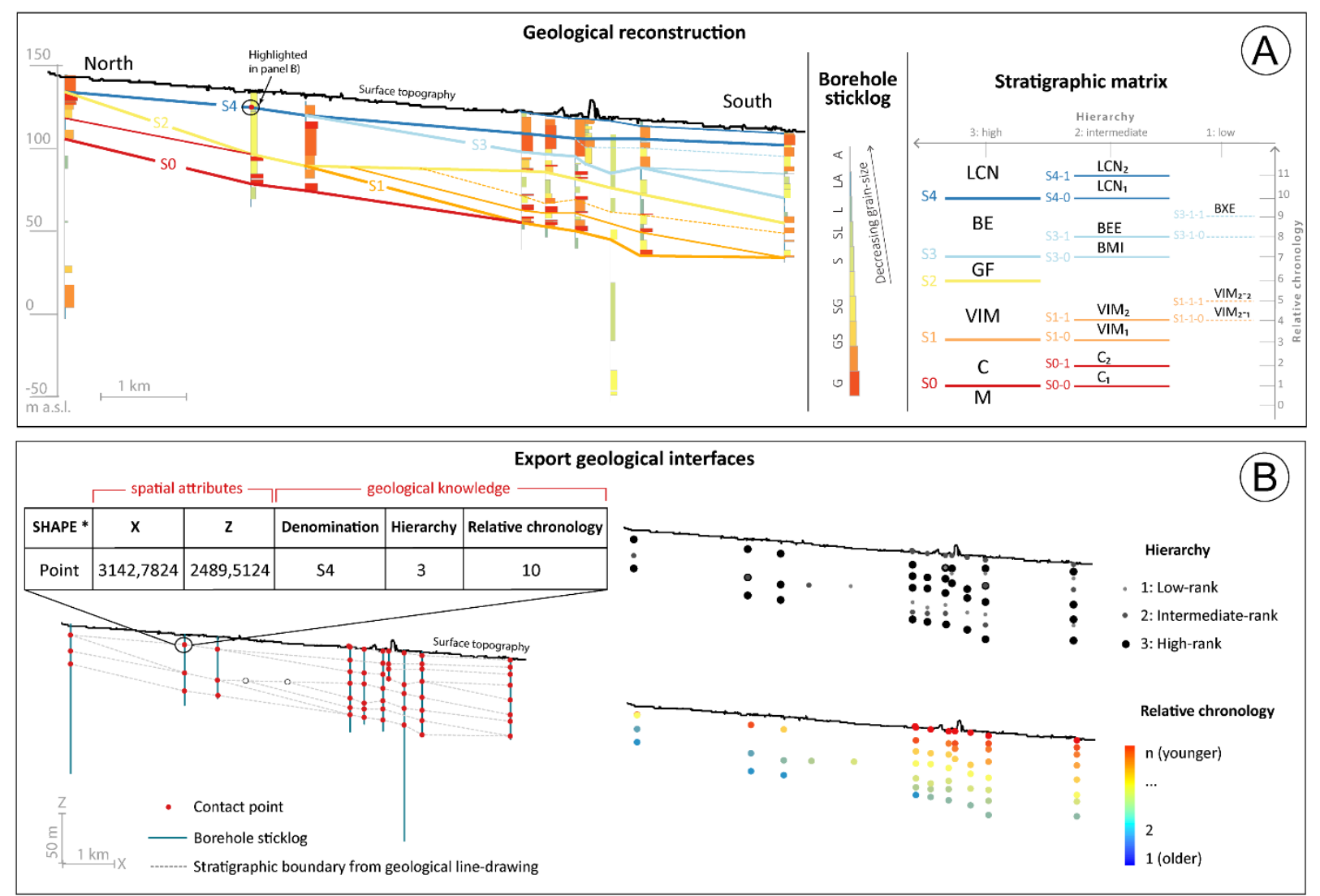

Fig. 4. A) Stratigraphic cross-section after 1-D borehole analysis along vertical sticklogs and 2-D hierarchic correlation. Vertical exaggeration 20x. Location of cross-section in Fig. 3-A. Lithotextural coding of borehole stratigraphy as in Table 1. B) GIS-based management of multi-dimensional, hierarchic elaborations as input data for numerical modelling: the point file processed at the intersections between the borehole sticklogs and the stratigraphic boundaries, carries both geometrical and spatial information (spatial attributes, left-hand side of Panel B) and interpretation on hierarchy and chronology (geological knowledge, visualized through specific symbols on the right-hand side). Two black circles on the left-hand section have been located to show that HIEGEO permits the user to locate some Sbounds terminations at different locations from the contact points, based on additional external information, to evaluate alternative geometries honouring all the data-points and the geological rules.

\subsection{Proposed formalism}

The result of the previous step is a 2-D network of hierarchically arranged stratigraphic boundaries and units as shown in Fig. 4-A. The following notations are then used to formalize the interpretation and label the stratigraphic boundaries:

- $\quad \mathrm{S} n$ represent the highest level in the hierarchy of stratigraphic boundaries, where $n$ represents their relative chronology $(n$ increases in ascending stratigraphic order);

- $\quad$ an index $m$ is added in the notation for the intermediate level in the hierarchy of stratigraphic boundaries, presented as Sn- $m$;

- $\quad$ an additional subscript, $l$, is added to represent the lowest level in the hierarchy of stratigraphic boundaries, presented as $\mathrm{S} n$ m-l;

- $\quad n, m$ and $l$ are integers representing the relative chronology of the stratigraphic boundaries at each hierarchical level (stratigraphic matrix of Fig. 4-A). 
The interpreted stratigraphic boundaries on the geological cross-section compose a set of GIS polylines with the following associated attributes: i) the above-mentioned stratigraphic classification using the $S n-m-l$ notation explained above, ii) hierarchy, and iii) relative chronology. Hierarchy is coded as integer numbers raising with hierarchic level (1 for the lowest, 3 for the highest in this example, see Fig. 4-A right); relative chronology is coded by numbers from zero to $N$, with zero corresponding to the bottom of the oldest stratigraphic unit (unit M in Fig. 4-A), while $N$ corresponding to the most recent event recorded by the geological history, independently from the hierarchy of the increments/events (read along the matrix rows; Fig. 4-A, right). To illustrate this proposed formalization, Fig. 4-A shows for example the polyline S3 that bounds the base of a group of three vertically stacked units (BMI, BEE, BXE). Relying on the previous definitions, $\mathrm{S} 3$ is a high-hierarchy boundary: it will be coded as hierarchy $1 / 43$; relative chronology $1 / 47$. S3 is truncated by the boundary S4, which has the same hierarchy. This cross-cut relation shows that S4 postdates S3 (the relative chronology of S4 will be coded as 10, according to the corresponding geological increment and the stratigraphic matrix shown in Fig. 4-A).

Since the quality of borehole log descriptions allowed to refine the correlation between S4 and S3 lines, other stratigraphic boundaries of lower hierarchy were traced: S3-0 and S3-1 of intermediate hierarchic order (hierarchy 1/4 2; Fig. 4-A). Each of them bounds a fining-upward sequence of decametric thickness (intermediate-hierarchy stratigraphic units BMI and BEE). The relative chronology is again fixed by the cross-cut relationship: S3-0 has a relative chronology 7 and predates S3-1, having therefore a relative chronology 8. Lastly, the lowest hierarchical level of stratigraphic boundary is illustrated with S3-1-1 (hierarchy $1 / 4$, relative chronology $1 / 49$, Fig. 4-A). It bounds the low-hierarchy stratigraphic unit BXE and has been interpreted and drawn above S3- 1. It is cross-cut by the high-hierarchy line $\mathrm{S} 4$ at relative chronology 10 .

\subsection{Consistency check}

The 2-D cross-section is checked for the internal consistency, non-contradiction, simplicity and likelihood criteria. In the example case, the relationships between the 2-D stratigraphic units and their bounding lines are simple. They are consistent and agree with the previous interpretations of the stratigraphic evolution of the region (Fig. 3-B; Bersezio et al., 2014; Bini et al., 2004; Cavalli, 2012). Yet, this interpretation is uncertain, and might be rejected at the end of modelling, to favour some alternative correlations based on new additional data or revisions of the correlation criteria (Fig. 2).

Comparing the 2-D cross-section and the available literature (Bersezio et al., 2014; Bini et al., 2014, 2004; Cavalli, 2012; Francani et al., 2016, Fig. 3-B) yields some suggestions on the geological evolution of the area. In the Early Pleistocene, uplift on the Northern Alpine side of the basin shaped the S0 and S1 erosion surfaces, at the base of incised alluvial valleys subsequently filled by transitional to alluvial deposits (units 'C' and 'VIM'; Fig. 4-A; Bersezio et al., 2014; Bini et al., 2014). These two major units are punctuated by minor cycles, framed by intermediate-hierarchy boundaries (units C1-C2 and VIM1-VIM2; Fig. 4-A). Since the end of Calabrian and during the Middle-Late Pleistocene, cyclical advances of the Alpine glaciers forced the glacio-fluvial depositional systems to spread from the North. The oldest glaciofluvial units (GF; Fig. 4-A, corresponding to the Bozzente, Binago and Specola synthems in Fig. 3-A) rest above the high-hierarchy unconformity S2. Uplift, S-ward tilting and glacial-interglacial cyclicity shaped the Middle-Late Pleistocene glacio-fluvial terraces (BE, Fig. 4-A; Besnate Supersynthem, Fig. 3-A), bounded at the base by unconformity S3. The latter results from the composition of the unconformities S3-0, S3-1 which sole at least two intermediate-hierarchy glaciofluvial units (Cadorago, BEE, and Minoprio, BMI, units; Fig. 4-A). The S4 high-hierarchy erosional boundary predates the S-ward progradation of the Late Pleistocene Laghi Supersynthem (LCN; Fig. 4-A). It contains two intermediate-hierarchy units (Fig. 4-A) which developed during the Last Glacial Maximum, sealing and/or cross-cutting the old terraces. The hierarchy and relative chronology of the stratigraphic units and boundaries, drawn in the cross-section after correlation, contribute to delineate a coherent, simple and likely geo-history, in the frame of the regional geology. At this stage of the workflow, the cross section presented in Fig. 4-A is accepted as a plausible, yet uncertain interpretative picture, which honours the hard data-points fixed at the boreholes.

\subsection{Data preparation for numerical computation}

The cross-section is now ready to set-up the numerical computation. This step (Fig. 2) focuses on the contact points and is illustrated in Fig. 4- B. The set of contact points (where the stratigraphic boundaries cross the well-logs) is obtained using the georeferenced GIS points at the intersections between the 1-D borehole stick-logs and the stratigraphic boundaries defined in the previous step (Fig. 4-B). The contact points carry both hard spatial attributes and geological knowledge which are stored as alphanumeric codes in their attribute table (Fig. 4-B). The spatial attributes concern the location of the interface along the cross-section and consist in the spatial coordinates $x$ and $z$, as distances measured from the axis origin in cross-section view. The denomination assigned to each contact point corresponds to the classification of the stratigraphic boundary which they contribute to correlate. The geological knowledge is stored as two numerical attributes "hierarchy" and "relative chronology" as defined in Section 4.2. In Fig. 4, for instance, the contact point picked at S4 bears hierarchy 3 (column) and relative chronology 10 (row) in the stratigraphic matrix at the right side of panel A. According to the stratigraphic matrix, a contact point can be obtained at the same intersection preserving equal relative chronology 10 , while bearing hierarchy 2 and will be denominated S4-0. It derives that the boundaries at the lowest level of hierarchy contribute to build intermediatehierarchy lines, and the latter merge into high-hierarchy boundaries. 


\section{Computational steps}

In the previous steps, the geological interpretation and the raw data have been coded to obtain a table, containing the coordinates of the contact points and their corresponding attributes (Fig. 4-B). In addition to the input table, HIEGEO reads a parameter file (JSON format) that contains information about the discretization grid, like the minimum and maximum $x$ and $z$ coordinates, and the size of the cells ( $\Delta x$ and $\Delta z$ ). A discretization grid is required to allow the export of the interpreted information into a structured grid file (VTK or GSLIB) and for the interpolation of the stratigraphic boundaries within the defined domain. Since the focus of this paper is the conceptualization of the geological knowledge, it was preferred to keep the interpolation step as simple as possible. Therefore, a linear interpolation algorithm is implemented to join the contact points belonging to the same stratigraphic boundary. Better interpolation methods can be implemented, either explicit or implicit (Wellmann and Caumon, 2018); however, we argue that it would be even better if existing geomodelling tools could integrate the proposed hierarchical framework. Our aim is not to replace those tools but rather to propose a novel way to code the stratigraphic pile.

\subsection{Stratigraphic boundaries (SBounds) and stratigraphic units (SUnits)}

All the computations are done in Python ${ }^{\mathrm{TM}}$ and use an object-oriented approach. Once all data have been read, the stratigraphic boundary objects (SBound class; Fig. 5-A) are instantiated. They represent the conceptualization of a geological stratigraphic boundary. They contain all the attributes related to a stratigraphic boundary, like the spatial coordinates of the contact points available to delineate them (attributes $x \_$raw and $z \_r a w$, Fig. 5-A) as well as the hierarchy and relative chronology (Fig. 2; Figs. 4, Fig. 5-A). In addition, the SBound class contains some methods used to plot a stratigraphic boundary object using the capabilities of the matplotlib graphical library, to interpolate it with piecewise linear interpolation (results are saved into the attributes $x d$ and $z d$, Fig. 5-A), or to get all the SBounds which lie above the current stratigraphic boundary.

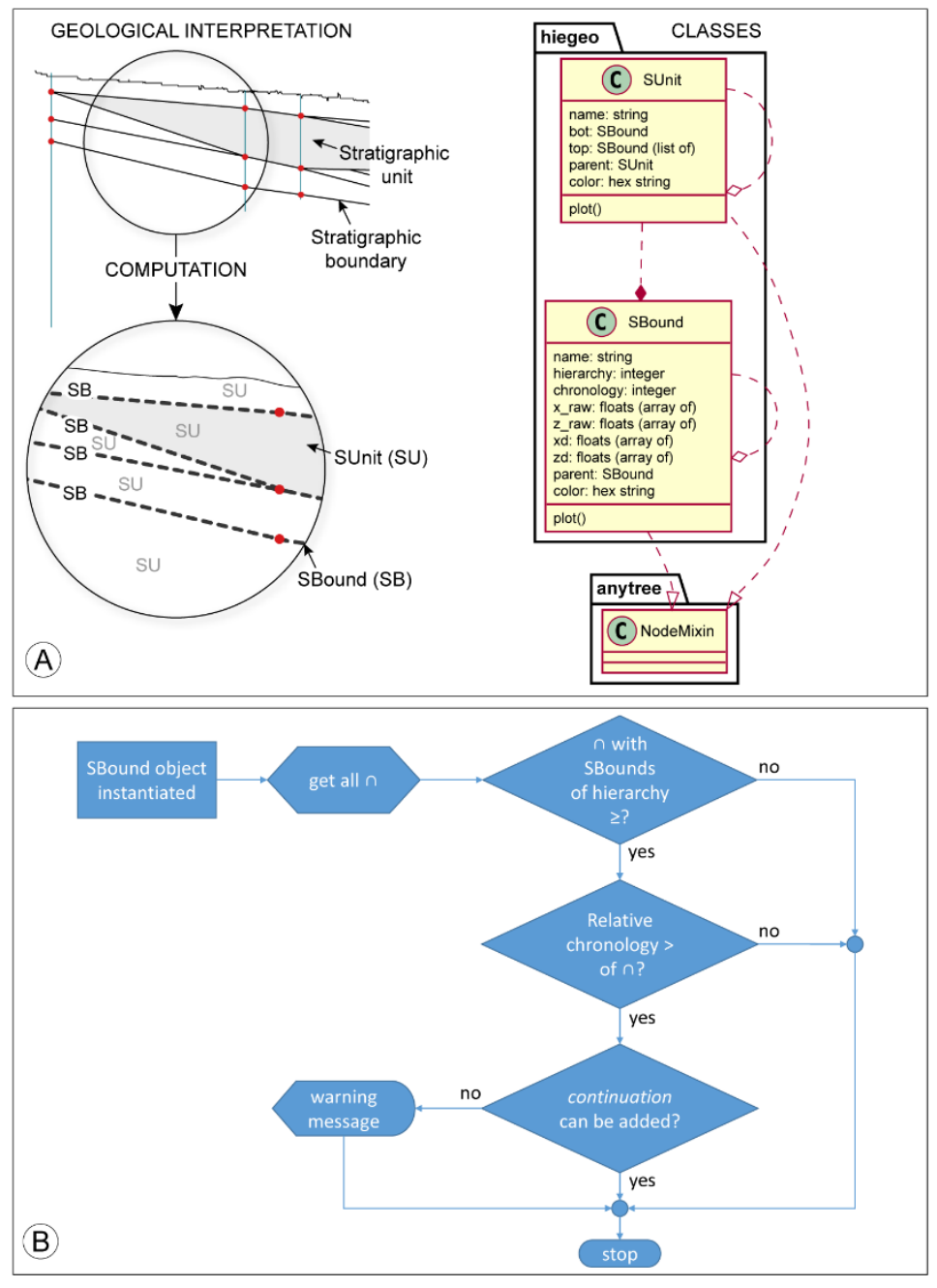

As illustrated in Fig. 5-A, the SBound class extends the class NodeMixin of the Python ${ }^{\mathrm{TM}}$ package anytree (https://gith ub.com/c0fec0de/anytree). This allows to better organize the SBound objects into a tree structure, also relying on the attribute parent (Fig. 5A), that contains a reference to the SBound object of a higher level of hierarchy.

SBounds are the boundaries that define the objects of type SUnit. The latter class implements the concept of stratigraphic unit and is defined given one bottom SBound and one or more SBounds for its top (bot and top attributes, Fig. 5-A). SBounds and SUnits are used to compute and visualize the geological model and to produce the 2-D graphical output. Almost all the steps required to create the geological model from the input data are automated and included in the function create_sb_from_data, which instantiates all the required SBound objects and returns them into a list. This is the preferred way to instantiate the SBounds, because they are instantiated in a sequence, starting from the highest-hierarchy, then moving to the lowest, allowing to properly fill the tree structure of the model. Alternatively, e.g. for testing purposes, advanced users can instantiate each SBound object separately by using the provided methods.

Fig. 5. A) Schematic representation of the concept of SBounds and SUnits, and their link with an UML diagram of the main classes defined in HIEGEO; the dots are the contact points. B) Flow-chart of the procedure embedded in the creation of a SBound object. The symbol $\backslash$ refers to a contact point where two or more SBounds are defined. 


\subsection{Core algorithm}

The core algorithms of HIEGEO create the SBound objects which define the SUnit objects in their corresponding hierarchic order. Considering that different low-hierarchy SBounds often merge into a higher hierarchy SBound object, HIEGEO permits to draw the lowhierarchy segments which compose the high-hierarchy SBounds, generating the bases of the Sunits of the corresponding hierarchy (for an example compare the cyan S3 boundaries in the geological cross-section in Fig. 4 and in Fig. 6), To do that, once the SBound class is instantiated, all the data are processed, and the arguments $x \_$raw and $z$ raw are extended to facilitate their representation (Fig. 5). As explained in Section 5.1, SBounds are instantiated in a precise order. When a SBound is instantiated, the algorithm checks if the SBound is in contact with any already instantiated SBound. By checking the nature of the contact points (hierarchy and relative chronology of the therein defined SBounds), it is possible to discern if the current SBound alone is enough to delineate the bottom of a stratigraphic unit (SUnit), or if the bottom derives from the composition of more than one SBound. In the latter case, a SBound is extended by adding the points (in the attributes $x_{-}$raw and $y_{-}$raw) required to properly complete the bottom of the corresponding SUnit. These points, which are borrowed from a SBound of higher hierarchical level, constitute a continuation line.

The details of the procedure are illustrated in the following (Fig. 5-B, Fig. 6): when a SBound is instantiated, all the corresponding contact points are checked to verify if any other SBound is therein defined. If that is the case, three additional checks are made. First, if the hierarchy of the current SBound is lower than the one of the other SBound, then there is the possibility to extend the current SBound with a continuation line, in order to represent a possible bottom of the corresponding stratigraphic unit. Second, if the relative chronology of the current SBound postdates the other SBound, there is again the possibility to extend the current SBound with a continuation line. A final check is made to verify if, how, and where the continuation line should be appended to the current SBound. For example, one should check if the continuation should be added to the left or to the right of the contact point. If the horizontal coordinates of the current SBound are coherent with those of the one intersecting it, then a continuation line is added. Otherwise, a warning message is printed, because at this stage, given the two previous checks and a properly provided data set for the coordinate $x$, a continuation is in general needed. Let us further illustrate this procedure with the example shown in Fig. 6 . We start by focussing on the case of the SBound denominated S3-1 and bearing hierarchy 1/4 2. At a first stage, SBounds of hierarchy $1 / 4$ are defined (including S3 and S4, Fig. 6-A). Once the SBound S3-1 is added, a contact point shared with S3 is found (highlighted point, Fig. 6-B). As the hierarchy of S3-1 is lower than the one of S3, S3-1 cannot cut S3; moreover, the relative chronology of the two SBounds makes that the bottom of the SUnit SU3-1 should coincide with S3 wherever the SBound S3-1 is not defined, that is on the left of the intersection between S3-1 and S3. Therefore, when the SBound object S3-1 is instantiated, a continuation line is added to its attributes to make it ready to represent the bottom of the corresponding stratigraphic unit (points along the highlighted segment of S3, Fig. 6-C). In the end, the polygonal SUnit SU3-1 can be properly added due to the correct definition of S3-1 (Fig. 6- D).

Moreover HIEGEO, while honouring the constraints given by the contact points, allows to include additional

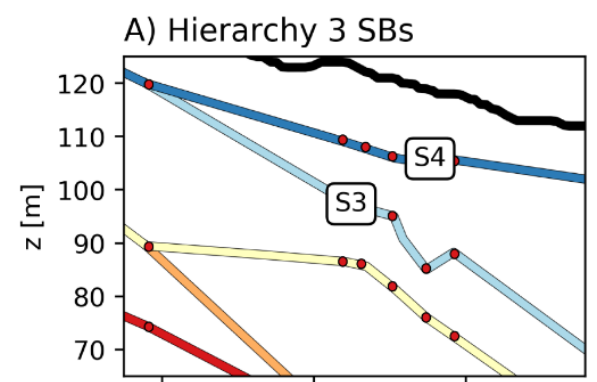

B) Add hierarchy 2, intersection
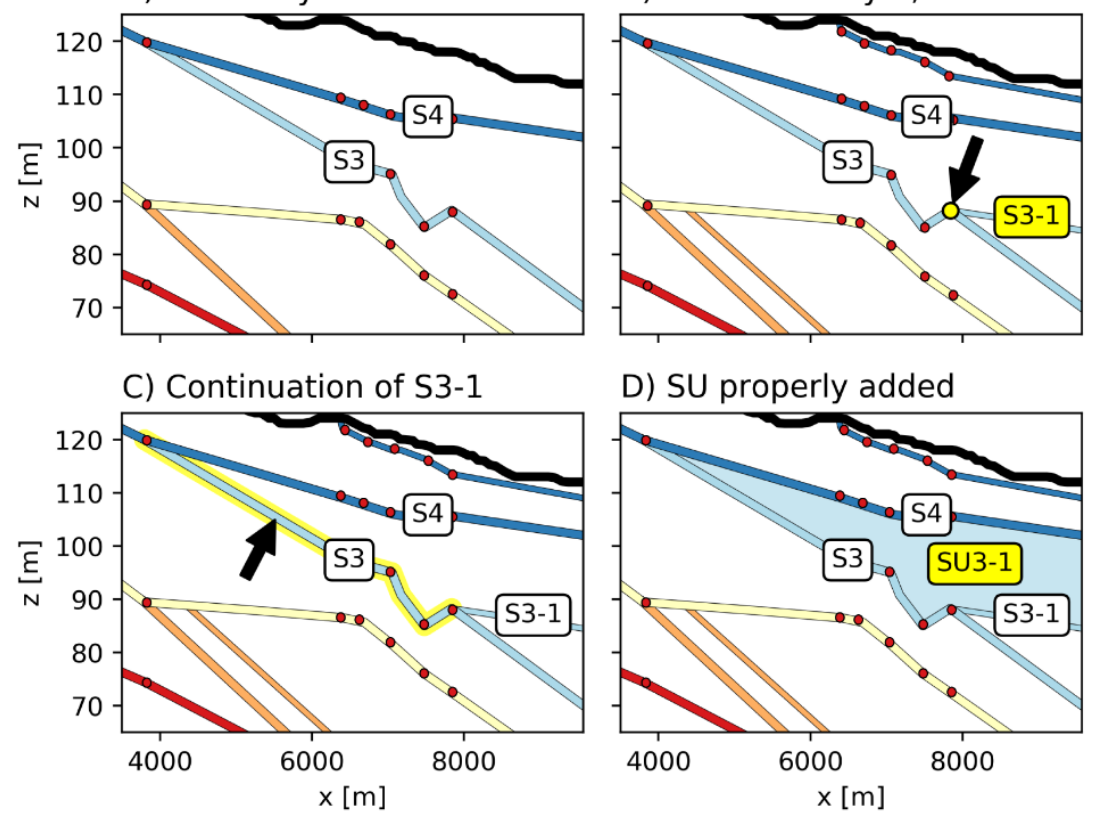

D) SU properly added

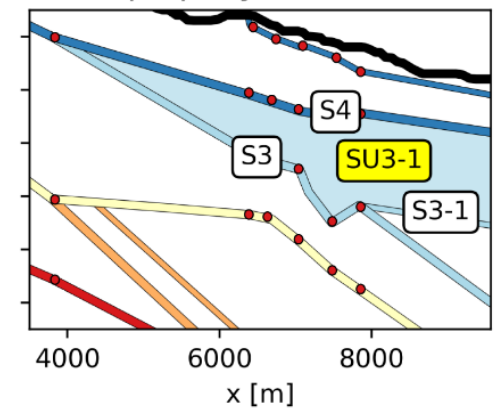

information in the interpolation process to refine the final representation. In the presented case-study, for example, the truncation of two stratigraphic boundaries was introduced from the geological interpretation, (two black circles in Fig. 4-B, left-hand section). Since the spatial coordinates of these points are uncertain, because they are not constrained by a well-log, they do not represent contact points. The formalization and interpolation of these additional points may help to draw the cross-cut relationships between the Sbounds, provided that no inconsistencies are introduced and the uncertainty on the location of these points is accounted for.

Fig. 6. Steps required to properly represent the SUnit SU3-1, starting from SBound S3-1. A) SBounds of hierarchy 3, S3 and S4, are added; B) once S3-1 is added, an intersection point is found; C) a continuation line is added to the SBound S3-1 to represent the bottom of the modelled SUnit SU3-1; D) finally, a SUnit can be properly added. Dots in each panel: contact points. 


\subsection{Model plot}

Once all the stratigraphic boundaries are instantiated as SBound Python ${ }^{\mathrm{TM}}$ objects, they can be plotted using the HIEGEO function plot_sb_ax. It allows to select up to which hierarchy the SBounds should be represented (see examples in Fig. 7-column A). This first step allows to detect inconsistencies present in the data-set or inborn in its interpretation. Some examples of inconsistent data are provided in Fig. 8 and will be discussed later in the text.

The SBound objects can be combined to plot the corresponding SUnit Python ${ }^{\mathrm{TM}}$ objects interposed between them. The HIEGEO module contains functions to automatically plot all the defined SUnits based on their hierarchy at the desired level of detail (Fig. 7-B). For example, by acting on the input arguments, the user can choose to plot the SUnits including either only hierarchy 3, or hierarchy 2 and 3 as well as all the available hierarchies (Fig. 7-B). Of course, the output of this modelling step is not limited to the plots presented in Fig. 7, but it is available also as a structured grid file (GeoEAS/GSLIB or VTK) that can be further processed, e.g. by geostatistical modelling tools.

Another useful tool provided by HIEGEO is the possibility to represent SBounds with a hierarchical tree structure (Fig. 7-C). This is built when the SBounds are instantiated, based on the hierarchy and relative chronology of the contact points, and is implemented using the anytree Python ${ }^{\mathrm{TM}}$. This figure allows to check if the interpreted stratigraphic hierarchy agrees with the geological knowledge that drove the construction of the data set.

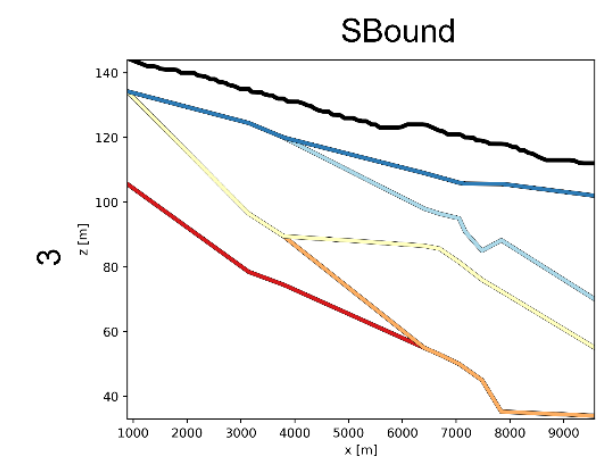

hiegeo output in terms of:
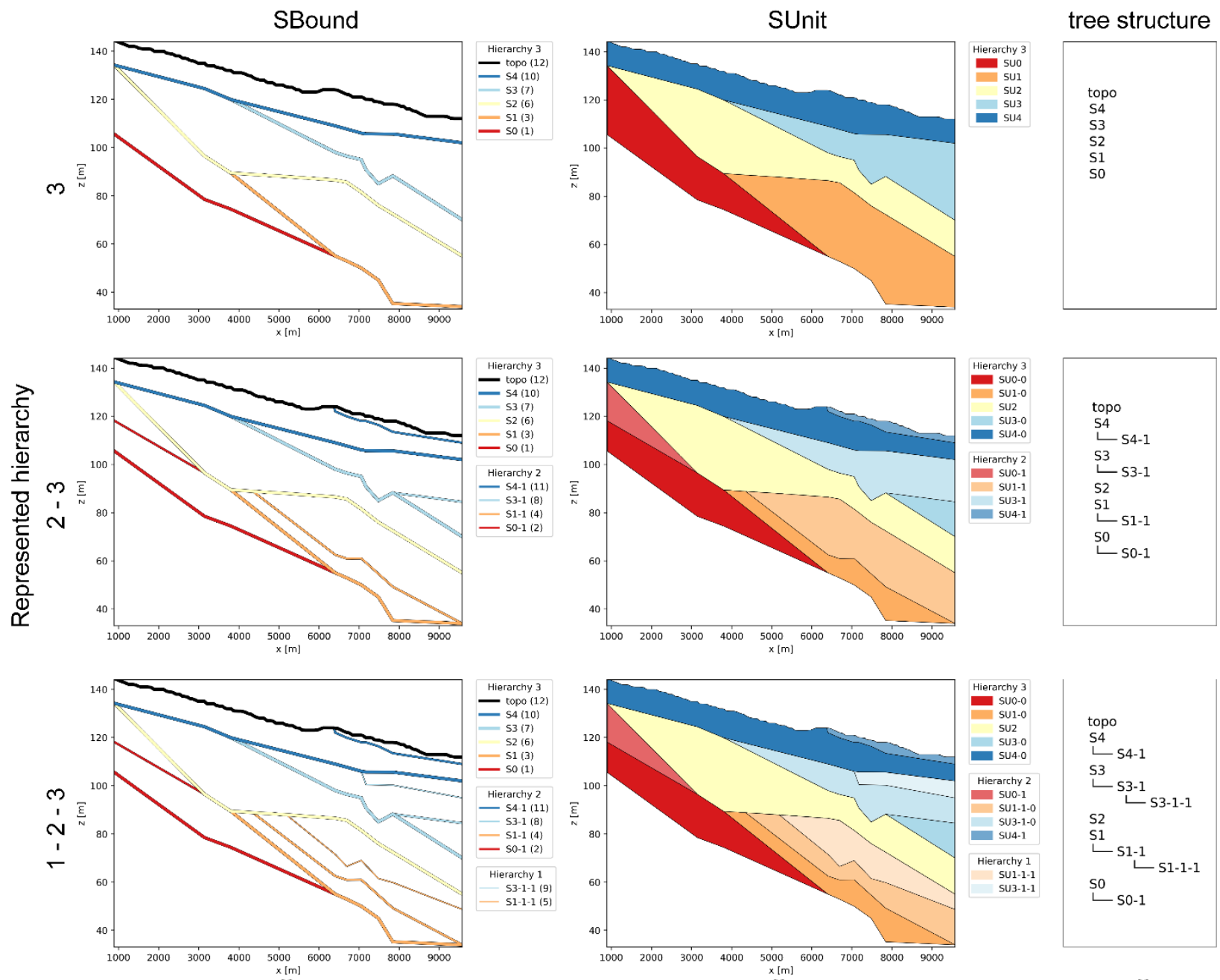

(A)

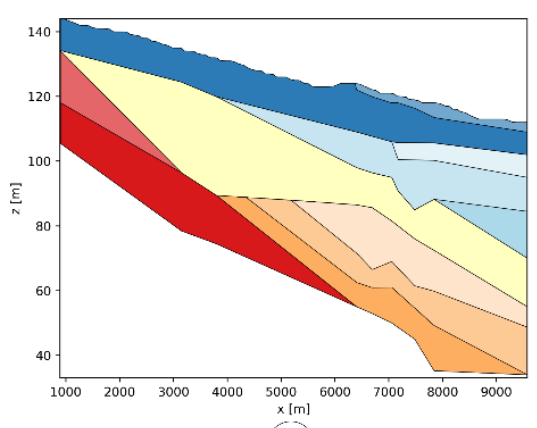

(B)

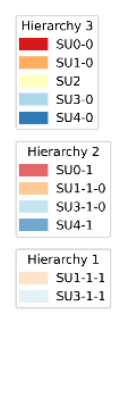

topo S4 $54-1$ S3 ᄂ S3-1 S3-1-1 S2 S1 S1-1 so

(C)

Fig. 7. Using HIEGEO it is possible to represent nested SBounds and SUnits at diverse levels of complexity. Column A): plot of the modelled Python ${ }^{\mathrm{TM}}$ objects SBounds; column B) plot of the modelled SUnits; column C) plot of the tree structure. Rows: the levels of hierarchy chosen for the plot, with the number of visualized hierarchies, i.e. model complexity, increasing towards the bottom. Compare to the interpreted cross-section of Fig. 4-A. Contact points are not shown for the sake of readability. 


\subsection{Model output and quality check}

The model automatically returns the stratigraphic architecture of the SBounds at multiple hierarchical levels (Fig. 7, column A), given the input table of contact points (Fig. 4-B). The modelled stratigraphic architecture (Fig. 7) is consistent with both the spatial attributes of the dataset and the geological knowledge (hierarchy and relative chronology). Each SBound intersects and connects the contact points of equal hierarchy and relative chronology, hence preserving the evolutionary interpretation of the geological architecture. The higher level of the hierarchy in stratigraphic architecture is shown in the upper row of Fig. 7. It comprises 5 high-hierarchy SUnits, i.e. the Python ${ }^{\mathrm{TM}}$ objects bounded by the SBounds of hierarchy 3 (lines labelled S0 to S4 in ascending stratigraphic/chronological order) comparable to the stratigraphic boundaries correlated in the subsurface of the study area (Fig. 4- A). The cross-cut relationships and the vertical stacking of the geological units, modelled at this hierarchy, are consistent with the erosional nature of their bounding surfaces. Hence, the multiple visualizations here proposed allow to check the internal geometry of the high-hierarchy stratigraphic units, showing their composite nature resulting from multiple erosionaldepositional events of lower-hierarchy. As an example, the interpreted 'Besnate Supersynthem' (stratigraphic unit 'BE' in Fig. 4 A), modelled and plotted as SUnit SU3 in Fig. 7, upper row, is the composition of the Minoprio Unit (BMI in Fig. 4-A) and Guanzate Unit (BEE, Fig. 4-A), resulting from two different depositional events which produced the nested geometries of SU3-0 and SU3-1 visualized in Fig. 7, central row. The output images are consistent with the geometrical and geological reconstruction represented in the 2-D cross-section.

When some inconsistency is present in the data-set, or when the hierarchy and relative chronology are misinterpreted by the user, HIEGEO allows to highlight potential problems in two ways. The first way consists in a warning/error message printed to the standard output. It occurs whenever the script cannot render any result starting from the input attributes of the contact points. The second way to highlight potential problems is the production of a graphical output whenever the incorrect input does not compromise the run of the script. The image can be analysed by the user, compared and discussed relatively to the interpreted geological cross-section (Fig. 4-A). Two examples are given in Fig. 8. Fig. 8-B illustrates the case when the input relative chronology of the boundaries S3 and S3-1 is inverted. Despite the hierarchic relationship is preserved (S3-1 stops against S3), the SBound S3-1 is not considered to subdivide the high-hierarchy SUnit SU3 into the two intermediate-hierarchy SUnits SU3-0 and SU3-1 (compare to Fig. 7-A). Fig. 8-C, instead, represents a case when a wrong hierarchy (hierarchy 1/4 2 in place of 3) is attributed to the boundary S3, while preserving the correct relative chronology of the stratigraphy. In this case, the script does not recognize any high-hierarchy SBound between S2 and S4, hence includes the whole modelled SUnit 3 ('SU3' in Fig. 7) within the SUnit 2 (SU2). The anomalies presented in both the situations represent cases when the answer to "model OK" in the flow chart of Fig. 2 is "NO". In this case, the user needs to check the starting geological dataset and verify step-by-step the dataset analysis, interpretation and predisposition to numerical modelling. 
SBound
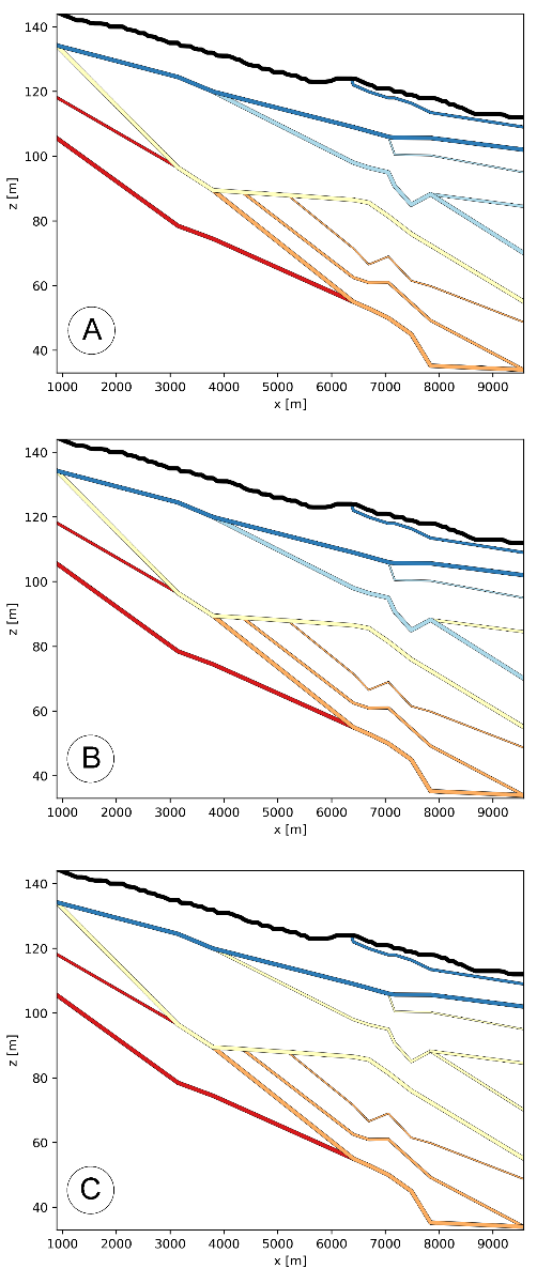

SUnit
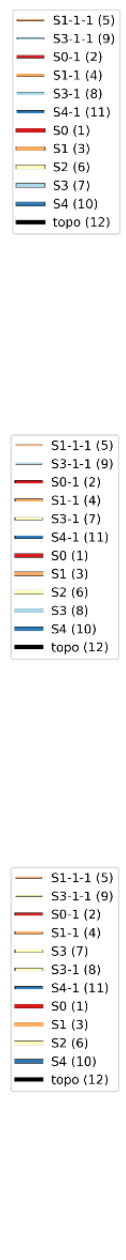
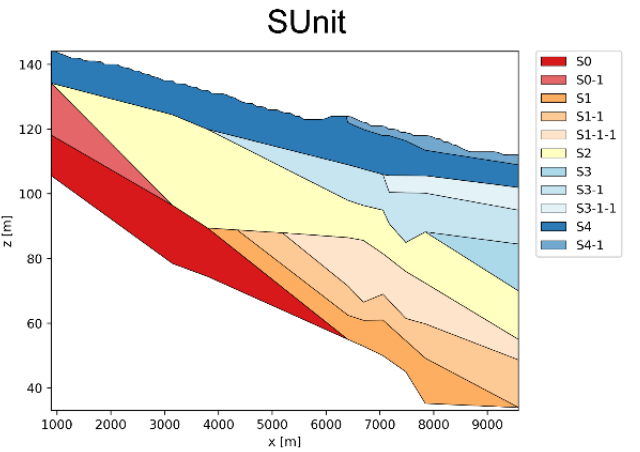

tree structure
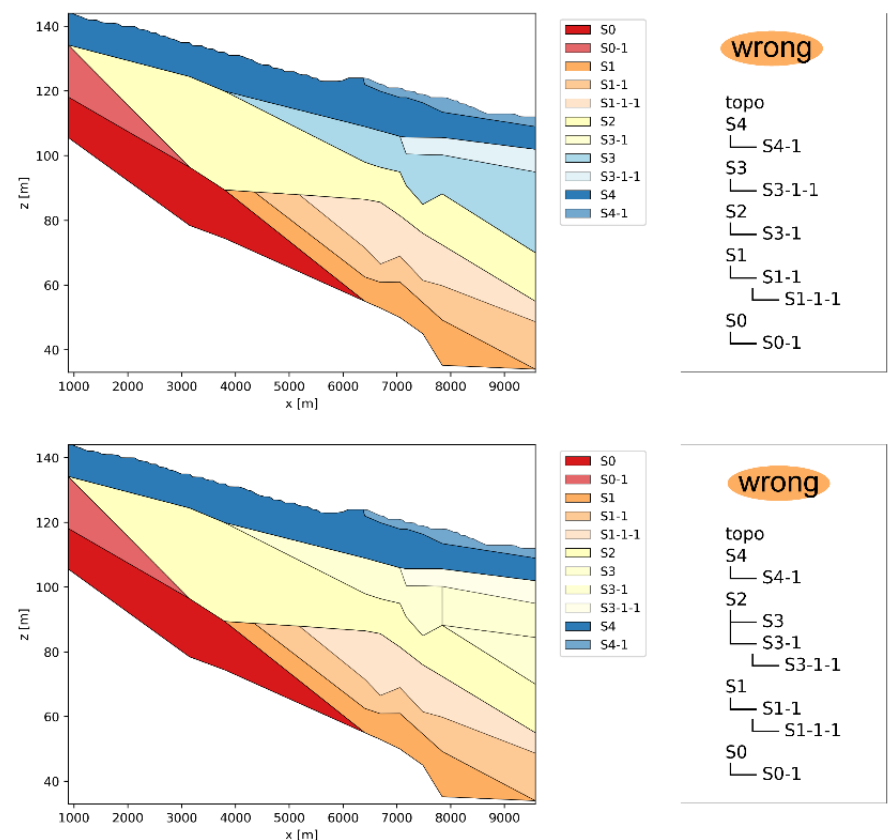

Fig. 8. Check of the model consistency. The model output when A) the input data are coherent, and B), C) when there is incoherence in input data. For each row, the geological model is provided in terms of stratigraphic boundaries on the left column, in terms of stratigraphic units in the middle columns, and in terms of hierarchical tree in the left column.

\section{Summary and conclusions}

The proposed workflow integrates hard geometrical constraints (spatial coordinates of the contact points) and shows how hierarchical rules can be employed in addition to relative chronology to delineate stratigraphic entities in a geological model. This was illustrated on the alluvial stratigraphy of the Po Plain sedimentary basin (Italy). The Python TM code HIEGEO demonstrates, by using a simple illustrative case, how the rules derived from the geological knowledge can be formalized, yielding modellin $\mathrm{g}$ constraints which reflect the geological history of the specific setting under investigation. A further step, far beyond the aims of this paper, might be the implementation of this approach in geomodelling codes, and especially for hydrostratigraphic and hydrogeological applications.

Here, we propose to consider the hierarchy and relative chronology simultaneously. It allows reproducing the external boundaries of the high-hierarchy units and the internal (lower-hierarchy) nested stratigraphic features almost simultaneously, following their genetic temporal ordering, no matter if synchronous or not within different high-rank domains (i.e. stratigraphic units). We are suggesting a sort of 4-D topology to account for the spatial and temporal relations among the geological objects contemporaneously.

In other words, as illustrated by the example, it is not necessary to reproduce the internal features of the high-hierarchy units separately within each individual domain, either recomposing the domains afterwards, or cutting-out the low-hierarchy features across the high-hierarchy boundaries ex post. How would HIEGEO model some coeval but physically separate bed-sets contained within a high-rank unit, or within two different high-rank units? The example clarifies that: i) the contact points and the stratigraphic matrix assign the subordinate units to their specific parents, ii) the "hierarchy" label constraints the no-cross relationships between their boundaries and the contours of their relatives (the same holds for the low-rank features they contain), iii) the "relative chronology" label constraints the topology among the equal-rank features throughout the entire domain, formed by the assemblage of the highest-rank entities as well as within the sub-domains inside them. We believe that this is a sufficiently 
straightforward way to link the spatial (hard) attributes and the related chronological attributes with the site-specific geo-history, independently from the physical scale and at any requested detail, through domains which might be as large as entire sedimentary basins or as small individual point-bars. If relative chronology and hierarchy are consistent, HIEGEO "must" find a solution. If not, the user will have to reconsider the geological correlation at the light of the geological evolution of the site. Should the user discover the pitfalls of the geological knowledge, they will have ensured the best cooperation between geologists and modelers. Some highlights on the HIEGEO workflow are recalled in the following sections.

\subsection{Hierarchic approach}

The workflow has been applied to a real case-study in the North of Italy and focuses on the still-debated geological complexity of the regressive sedimentary fill of the Po Basin during Quaternary. Five high-hierarchy geological boundaries were traced in the subsurface of the study area. The hierarchic approach adopted since the geological interpretation steps, permitted to draw and then model the composite nature of these stratigraphic boundaries, formed by nested, lower-hierarchy stratigraphic surfaces originated during shorter changes in depositional dynamics (Cavalli, 2012; Ghielmi et al., 2013; Scardia et al., 2012; Zuffetti et al., 2018; Zuffetti, 2019).

\subsection{Formalization of the geological knowledge}

The modelling workflow is based on a decomposition of the knowledge of the site-specific geological architecture into its components: the geometry of the stratigraphic entities, their hierarchy, and the relative chronology of the geological evolution, which can be managed as separate, numerical entities. The geometries resulting from the interpretation of the geological data set, in the form of a cross section, are expressed in terms of location of the contact points, i.e. the intersections between the stratigraphic boundaries and the borehole stick-logs. According to the geological knowledge, each contact point bears the description of cross-cut relationships, their erosional/depositional nature and chronological ordering that have been here formalized and converted into modelling rules within a rigorous automatic routine. The rules can be easily adjusted by the user to manage the geometrical and topological relationships between the modelled stratigraphic boundaries and units, i.e. to manage the geological uncertainty.

The site-specific geological knowledge includes: i) the "hierarchy" code, that is the relative position of the stratigraphic entities (boundaries and units) nested in the tree-structure of the stratigraphic succession. Stratigraphic hierarchy derives from the duration and rate of the genetic erosional/depositional processes, the more durable processes originating the highest-rank entities. Independently from the relative chronology, high-hierarchy erosional surfaces always cross-cut the low-hierarchy ones, not vice versa. Seemingly, high-rank depositional surfaces are composed by low-rank ones, not vice versa; ii) the "relative chronology" code describes the increments of the geological evolution trough time and is expressed as the vertical stacking, cross-cut, and lateral juxtaposition of stratigraphic boundaries and units of different hierarchy. In combination to hierarchy, it controls the order in which the cross-cut relationships must be modelled. These are the main rules implemented in the HIEGEO Python ${ }^{\mathrm{TM}}$ module to handle the representation of stratigraphic boundaries and stratigraphic units within a computer code.

The set-up of a GIS-based Geo-Database provided a consistent support for handling multi-scale dataset and for predisposing geological data to modelling. A rigorous GIS-based procedure has been here proposed to convert an interpreted stratigraphic cross-section into a set of georeferenced geological contacts ("contact points"), preserving both spatial attributes and geological knowledge as alphanumeric attributes (Fig. 4-B), to be used as input for spatial interpolation.

\subsection{A blueprint for multiscale geological modelling tools}

The interpolation of the stratigraphic boundaries using the proposed hierarchic workflow allows to preserve the link between geological interpretation of stratigraphic architecture and the resulting geological model, as exemplified by the model output shown in Fig. 7. The workflow is flexible, since it allows to easily add/modify data points as soon as new data are available and/or the interpretation is updated. To our knowledge, none of the available geological modelling platforms can simultaneously include hierarchy and relative chronology of the geological evolution as constraints in model building. Therefore, rather than supply ing a thorough computer code, the present work might provide a new perspective to approach geological modelling at diverse scales. The routines contained in HIEGEO allow to build a comprehensive multiscale model that encompasses high-, intermediate- and low-hierarchies of the stratigraphic architecture at the same time (Fig. 7). The HIEGEO module is provided as free and opensource software (FOSS). It can be easily adapted to different case-studies, or integrated in other modelling tools. It is a blueprint, in the sense that for illustration purposes the demonstration is made in 2-D and using an interpolation method (piecewise linear interpolation) that has many limitations. Nevertheless, the illustrative example is applied to a real-world case study, it is based on a real-world data-set and tackles the geological complexity which is typical of alluvial basins investigated for their groundwater resources. 


\subsection{Compatibility with further 3-D modelling workflows}

The natural development of the presented workflow is the modelling of stratigraphic architectures in 3-D. This could be achieved, for example, by integrating the steps proposed in the HIEGEO module into existing 3-D modelling suites such as GemPy (de la Varga et al., 2018), also belonging to the FOSS software and written in Python ${ }^{\mathrm{TM}}$ too, or within other proprietary modelling platforms like GeoModeller (Calcagno et al., 2008). Indeed, the potential field interpolation methods implemented in the aforementioned software would beneficiate by the integration of the geological knowledge rules formalized in the present work. These rules would introduce important constraints to control stratigraphic relationships, allowing representations of many orders of nested geometries. The optimum outcome would be to allow the 3-D stratigraphic architecture to be modelled in its hierarchic structure, accordingly to the geological interpretation, and in which the hierarchy could be visualized as a function of the scale and purposes of work.

In conclusion, a new modelling perspective relying on descriptive information of geological knowledge is set up. It constraints architectural models with hierarchical and chronological rules. We implemented and demonstrated its applicability with the FOSS software HIEGEO. The main advantages of the proposed workflow are: i) strong and traceable linkage between the modelled geometries and their geological origin; ii) representation of the geological architectures at different degrees of detail, in compliance with the detail of the available data; iii) possibility to represent diverse levels of hierarchical complexity, depending on the user's needs; iv) wide applicability to different contexts, and possible extension to 3-D modelling.

\section{Authorship statement}

$\mathrm{CZ}$ and RB conceived the presented idea, provided the geological data-frame and wrote the manuscript. AC developed the PythonTM script, performed computations and wrote the section related to the modelling procedure. PR aided in interpreting the results and worked on the manuscript. RB and PR supervised the findings of this work.

\section{Computer code availability}

The Python ${ }^{\mathrm{TM}}$ module HIEGEO can be downloaded and checked at the following link: https://bitbucket.org/alecomunian/hiegeo. Developer: Alessandro Comunian. Dipartimento di Scienze della Terra, Università degli Studi di Milano, via Cicognara 7, 20129 I-Milano, Italy. alessandro.comunian@unimi.it.

\section{Funding}

This work was supported by funds to RB [grant-RV_ATT_COM16RBERS_M] and to AC [grant-PSR2018_ACOMUNIAN].

\section{Declaration of competing interest}

No potential conflict of interest was reported by the authors. Acknowledgments The final version of the manuscript benefits from the thoughtful suggestions of F. Wellmann and two anonymous Referees.

\section{References}

Aigner, T., Heinz, J., Hornung, J., Asprion, U., 1999. A hierarchical process-approach to reservoir heterogeneity: examples from outcrop analogues. Bull. du Cent. Rech. Elf Explor. Prod. 22, 1-11.

Allen, P.A., Allen, J., 2013. Basin analysis: Principles and application to petroleum play assessment. John Wiley and Sons.

Bayer, P., Huggenberger, P., Renard, P., Comunian, A., 2011. Three-dimensional high resolution fluvio-glacial aquifer analog: Part 1: Field study. J. Hydrol. 405, 1-9. https://doi.org/10.1016/j.jhydrol.2011.03.038

Bersezio, R., 2007. Aquifer analogues. Mem. Descr. della Cart. Geol. d'Italia LXXVI, 39-50.

Bersezio, R., Bini, A., Gelati, R., Ferliga, C., Rigamonti, I., Strini, A., 2014. Note illustrative della Carta Geologica d'Italia alla scala 1:50.000. Foglio 097 Vimercate.

Bersezio, R., Bini, A., Giudici, M., 1999. Effects of sedimentary heterogeneity on groundwater flow in a Quaternary pro-glacial delta environment: Joining facies analysis and numerical modelling. Sediment. Geol. 129, 327-344. https://doi.org/10.1016/S0037-0738(98)00145-6

Bersezio, R., Zuffetti, C., Cavalli, E., Baio, M., Cantone, M., Inzoli, S., Pavia, F., Rigato, V., Rusnighi, Y., Rodondi, C., Sozzi, S., 2016. The Quaternary N-Apennine tectonics recorded in the Po Basin: stratigraphic and geomorphological evidences along a N-S traverse in Lombardy (Italy ). Geophys. Res. Abstr. 18 .

Bini, A., Sciunnach, D., Bersezio, R., Scardia, G., Tomasi, F., 2014. Note illustrative della Carta Geologica d'Italia alla scala 1:50.000. Foglio 96 - Seregno. ISPRA.

Bini, A., Strini, A., Violanti, D., Zuccoli, L., 2004. Geologia di sottosuolo dell'Alta Pianura a NE di Milano. Quat. 17, $343-354$.

Blum, M.D., Törnqvist, T.E., 2000. Fluvial responses to climate and sea-level change: a review and look forward. Sedimentology 47, 2-48. https://doi.org/10.1046/j.1365-3091.2000.00008.x

Bond, C.E., 2015. Uncertainty in structural interpretation: Lessons to be learnt. J. Struct. Geol. 74, 185-200. https://doi.org/10.1016/j.jsg.2015.03.003

Bridge, J.S., 2003. Rivers and Floodplains: Forms, Processes and Sedimentary Record. Blackwell, Oxford, UK.

Brodaric, B., Gahegan, M., 2001. Learning geoscience categories In Situ: Implications for geographic knowledge representation. Proc. ACM Work. Adv. Geogr. Inf. Syst. 130-135

Calcagno, P., Chilès, J.P., Courrioux, G., Guillen, A., 2008. Geological modelling from field data and geological knowledge Part I. Modelling method coupling 3D potential-field interpolation and geological rules. Phys. Earth Planet. Inter. 171, 147-157. https://doi.org/10.1016/j.pepi.2008.06.013

Calcagno, P., Courrioux, G., Lopez, S., Bourgine, B., 2018. How Geological Architecture Helps 3D Modelling, in: 4th Meeting of the European 3D GeoModelling Community. Orléans, France. 
Caumon, G., 2010. Towards stochastic time-varying geological modeling. Math. Geosci. 42, 555-569. https://doi.org/10.1007/s11004-010-9280-y

Cavalli, E., 2012. Messa a punto di una metodologia per la modellazione tridimensionale e multiscala dell'idrostratigrafia, su base Gis, PhD Thesis. Università degli Studi di Milano. Milano.

Chilès, J.P., Aug, C., Guillen, a, Lees, T., 2004. Modelling the Geometry of Geological Units and its Uncertainty in 3D From Structural Data: The Potential-Field Method. Orebody Model. Strateg. Mine Plan. - Spectr. 14 22-24.

Comizzoli, G., Gelati, R., Passeri, L. D., 1969. Note illustrative della Carta Geologica d'Italia. F. ${ }^{\circ} 45$ e F. ${ }^{\circ} 46$ - Milano e Treviglio. Servizio Geologico d’Italia, Roma.

Comunian, A., De Micheli, L., Lazzati, C., Felletti, F., Giacobbo, F., Giudici, M., Bersezio, R., 2016. Hyerarchical simulation of aquifer heterogeneity: implications of different simulation settings on solute-transport modeling. Hydrogeol. J. 24, 319-334.

Comunian, A., Renard, P., Straubhaar, J., Bayer, P., 2011. Three-dimensional high resolution fluvio-glacial aquifer analog - Part 2: Geostatistical modeling. J. Hydrol. 405, 10-23. https://doi.org/10.1016/j.jhydrol.2011.03.037

Dalman, R.A.F., Weltje, G.J., 2008. Sub-grid parameterisation of fluvio-deltaic processes and architecture in a basin-scale stratigraphic model. Comput. Geosci. 34, 1370-1380. https://doi.org/10.1016/j.cageo.2008.02.005

deKemp, E.A., Sanborn-Barrie,M., and St-Onge, M.R., 2007. 3D model Kattiniq (Raglan Mine) region; in: At-las géoscientifique numérique, ceinture de Cape Smith et environs, péninsule d'Ungava, Québec-Nunavut/Digital geoscience atlas of the Cape Smith Belt and adjacent domains, Ungava Peninsula, Quebec-Nunavut;StOnge,MR; Lamothe, D; Henderson, I; Ford, A; Geological Sur-vey of Canada, Open File 5117.

de la Varga, M., Schaaf, A., Wellmann, J.F., 2018. GemPy 1.0: open-source stochastic geological modeling and inversion.

Dell'Arciprete, D., Bersezio, R., Felletti, F., Giudici, M., Comunian, A., Renard, P., 2012. Comparison of three geostatistical methods for hydrofacies simulation: A test on alluvial sediments. Hydrogeol. J. 20, 299-311. https://doi.org/10.1007/s10040-011-0808-0

Dell'Arciprete, D., Felletti, F., Bersezio, R., 2010. Simulation of Fine-Scale Heterogeneity of Meandering River Aquifer Analogues: Comparing Different Approaches, in: Atkinson, P., Lloyd, C. (Eds.), geoENV VII - Geostatistics for Environmental Applications. Quantitative Geology and Geostatistics. Springer, Dordrecht, pp. 127-137. https://doi.org/https://doi.org/10.1007/978-90-481-2322-3_12

Francani, V., Piccin, A., Credali, M., Berra, F., Battaglia, D., Gattinoni, P., Rigamonti, I., Rosselli, S., 2016. Note illustrative della Carta Geologica d'Italia alla scala 1:50.000. Foglio 118 - Milano. ISPRA, Piacenza.

Gallerini, G., De Donatis, M., 2009. 3D modeling using geognostic data: The case of the low valley of Foglia river (Italy). Comput. Geosci. 35, $146-164$. https://doi.org/10.1016/j.cageo.2007.09.012

Gardner, M.H., 1995. The stratigraphic hierarchy and tectonic history of the Mid-Cretaceous foreland basin of Central Utah. Stratigr. Evol. Forel. Basins SEPM Speci.

Ghielmi, M., Minervini, M., Nini, C., Rogledi, S., Rossi, M., 2013. Late Miocene-Middle Pleistocene sequences in the Po Plain - Northern Adriatic Sea (Italy): The stratigraphic record of modification phases affecting a complex foreland basin. Mar. Pet. Geol. 42, 50-81. https://doi.org/10.1016/j.marpetgeo.2012.11.007

Heinz, J., Kleineidam, S., Teutsch, G., Aigner, T., 2003. Heterogeneity patterns of Quaternary glaciofluvial gravel bodies (SW-Germany): Application to hydrogeology. Sediment. Geol. 158, 1-23. https://doi.org/10.1016/S0037-0738(02)00239-7

Huggenberger, P., Aigner, T., 1999. Introduction to the special issue on aquifer-sedimentology: problems, perspectives and modern approaches. Sediment. Geol. 129, 179-186. https://doi.org/10.1016/S0037-0738(99)00101-3

Jussel, P., Stauffer, F., 1994. Transport modeling in heterogeneous aquifers : 1. Statistical description and numerical generation of gravel deposits of the aquifer. Water Resour. Res. 30, 1803-1817.

Lemon, A. M., Jones, N. L., 2003. Building solid models from boreholes and user-defined cross-sections. Computers \& Geosciences 29 (5), $547-555$.

Mackey, S.D., Bridge, J.S., 1992. A revised FORTRAN progra to simulate alluvial stratigraphy. Comput. Geosci. Geosci. 18, 119-181. https://doi.org/10.1016/00983004(92)90080-B

Macrae, E.J., Bond, C.E., Shipton, Z.K., Lunn, R.J., 2016. Increasing the quality of seismic interpretation. Interpretation 4, T395-T402. https://doi.org/10.1190/INT2015-0218.1

Miall, A.D., 1996. The geology of fluvial deposits: sedimentary facies, basin analysis and petroleum geology. Springer-Verlag, Heidelberg.

Miall, A.D., 1985. Architectural-element analysis: A new method of facies analysis applied to fluvial deposits. Earth-Science Rev. 22, 261-308. https://doi.org/10.1016/0012-8252(85)90001-7

Perrin, M., Rainaud, J.-F., 2013. Shared Earth Modeling: Knowledge Driven Solutions for Building and Managing Subsurface 3D Geological Models. Technip, Paris.

Randle, C.H., Bond, C.E., Lark, R.M., Monaghan, A.A., 2018. Can uncertainty in geological cross-section interpretations be quantified and predicted? Geosphere 14, 1087-1100. https://doi.org/10.1130/GES01510.1

Russell, H.A.J., Kemp, E. De, Maccormack, K.E., 2019. Overview of Geological Survey Organizations Contributions on Modelling Approaches, in: MacCormack, K.E., Berg, R.C., Kessler, H., Russell, H.A.J., Thorleifson, L.H. (Eds.), 2019 Synopsis of Current Three-Dimensional Geological Mapping and Modelling in Geological Survey Organiza- Tions. Alberta Energy Regulator / Alberta Geological Survey, pp. 7-18.

Scardia, G., De Franco, R., Muttoni, G., Rogledi, S., Caielli, G., Carcano, C., Sciunnach, D., Piccin, A., 2012. Stratigraphic evidence of a Middle Pleistocene climatedriven flexural uplift in the Alps. Tectonics 31, n/a-n/a. https://doi.org/10.1029/2012TC003108

Schetselaar, E., Pehrsson, S., Devine, C., White, D., Malinowski, M., 2016. 3-D geologic modeling of the Flin Flon Mining District, Trans-Hudson Orogen, Canada: Evidence for polyphase imbrication of the Flin Flon-777-Callinan volcanogenic massive sulfide ore system. Economic Geology, 111, 4, 877-901.

Turner, A.K., 2006. Challenges and trends for geological modelling and visualisation. Bull Eng Geol Env 65, 109-127. https://doi.org/10.1007/s10064-005-0015-0

Weber, K.J., 1986. How heterogeneity affects oil recovery, in: Lake, L.W., Carrol, H.B.J. (Eds.), Reservoir Characterization. Academic Press, Inc., pp. $487-544$.

Wellmann, F., Caumon, G., 2018. 3-D Structural geological models: Concepts, methods , and uncertainties. Adv. Geophys. 59, 1-121. https://doi.org/?10.1016/bs.agph.2018.09.001

Wellmann, J.F., Lindsay, M., Poh, J., Jessell, M., 2014. Validating 3-D structural models with geological knowledge for improved uncertainty evaluations. Energy Procedia 59, 374-381. https://doi.org/10.1016/j.egypro.2014.10.391

Wijns, C., Boschetti, F., Moresi, L., 2003. Inverse modelling in geology by interactive evolutionary computation. J. Struct. Geol. 25, 1615-1621. https://doi.org/10.1016/S0191-8141(03)00010-5

Zappa, G., Bersezio, R., Felletti, F., Giudici, M., 2006. Modeling heterogeneity of gravel-sand, braided stream, alluvial aquifers at the facies scale. J. Hydrol. 325, 134-153. https://doi.org/10.1016/j.jhydrol.2005.10.016

Zuffetti, C., 2019. Characterization and modelling of complex geological architectures: The Quaternary fill of the Po Basin at the Po Plain-Apennines border (Lombardy, Italy), PhD Thesis. Università degli Studi di Milano. Milano.

Zuffetti, C., Trombino, L., Zembo, I., Bersezio, R., 2018. Soil evolution and origin of landscape in a late Quaternary tectonically mobile setting: the Po Plain-Northern Apennines border in Lombardy (Italy). Catena 171, 376-397. https://doi.org/10.1016/j.catena.2018.07.026 